business schemes (for example, methods of office management); (iii) commercial, financial and propaganda schemes; (iv) treatment of human beings; (v) designs or arrangements in which the novelty resides solely in appeal to the eye, (vi) designs or arrangements which serve only to convey information and in which the novelty resides solely in the information conveyed.

The Group recommends that adequate steps should be taken to enlighten agricultural interests as to the changes in the United Kingdom law which are contemplated and to explain the reasons for these changes.

The Group points out that the unification Convention does not completely solve the problem of how to resolve conflict with prior unpublished applications. Article 6 of the Convention broadly requires that parties of the Convention shall not allow double patenting. The present statutory provisions in the United Kingdom rest basically on the principle that double patenting is to be avoided, but the interpretation given to these provisions in recent years has produced serious difficulties. The Group agreed generally that a straightening out of United Kingdom law is necessary to bring some real sense into this subject quite apart from the requirements of the Convention. Generally, the Group is also agreed that a later patent should not be granted if it purports to prevent the working of the invention as claimed in an earlier patent in any manner in which a competent person would normally work it. Some suggested forms of wording for this 'prior claim' proposal are appended to the report. Nevertheless, the Group concludes that there should be no requirement that a patent granted on the earlier application should be granted, or valid if granted.

\title{
THE FUTURE OF NUCLEAR POWER
}

\begin{abstract}
$\mathrm{T}_{\mathrm{H}}^{\mathrm{H}}$ HE John Macrossen Lecture was given by Sir John Cockcroft in the same year as the third International Conference on Atomic Energy was held at Geneva. The Lecture is a very brief staternent of the prospects of the economic development of nuclear power at that date, a subject very fully dealt with at Geneva. The capital costs per $\mathrm{kW}$ of electricity generated by the stations built by industry for the Central Electricity Generating Board will almost have halved in the 6 years between the completion of the 275-MW Berkeley station and the 1,180-MW Wylfa nuclear station, each of them containing two reactors. The fall is due in large part to the increased size of the unit; fuel costs have also fallen, but the overall cost of power by any calculation is still higher than that from coal-fired stations of the same dates.

The advanced type of gas-cooled reactor was expected in 1964 to cost less than a coal station of the same date, and within a year of the delivery of this Lecture the firm tender prices for the Dungeness $B$ nuclear station showed that this was, in fact, the case, provided the station is built at the tender price.
\end{abstract}

In the United States similar dramatic falls in costs have been experienced with their water moderated reactors; and Canada's heavy-water reactor is expected to have very low fuel costs, although it will have a high capital cost.

These types of reactors, by the end of the century, would be using 100,000 tons of uranium per annum, on reasonable assumptions as to the rate of development of nuclear stations. To avoid a rise in the cost of raw materials, more of the uranium-238 must be used; the experimental fast reactor at Dounreay has operated well enough now to justify a design study for a 1,000-MW reactor to be ready for the late 1970's; this might herald a new generation of stations to use up the plutonium from the slow-neutron reactors and the fast reactor might breed $\mathbf{1 . 5}$ times the amount of fuel it uses.

Fusion reactions still remain as a possibility and as a hope for the future; stability of the confined plasma at low pressures has been achieved but not at high densities. It would be idle at present to predict whether these schemes will be successful.

T. E. Allimone

\section{NUMERICAL METHODS IN SUBSONIC FLUID DYNAMICS}

A

SYMPOSIUM on "Numerical Methods in Subsonic Fluid Dynamics" was held at the National Physical Laboratory during September 27-29, 1965, the local organization being shared jointly by the Aerodynamics and Mathematics Divisions. More than one hundred and thirty visitors from industry, universities, technical colleges and Government establishments, including several from Europe and the United States, participated in the programme, which was divided into four sessions, each consisting of two general survey lectures followed by three parallel discussion groups $A, B$ and $C$. The subjects of the discussion groups were arranged so that $A$ was a follow-up of the general lectures of the session, $B$ was an independent subject introduced by a scheduled talk, and $C$ was a more specialized subject determined by popular demand from the participants themselves.

The original initiative for the meeting came from the Aeronautical Research Council, which had some two years ago anticipated the need for a comprehensive examination of the role of the computer in fluid dynami cs by setting up a Computer Panel. Quite early on, it became clear to the Panel that the full potentialities of the modern 'third generation' computer were not being adequately explored; consequently this symposium was arranged with the objects of elucidating some of the problems involved in the application of computers to fluid motions, and of stimulat- ing interest in the exploration of new approaches to the subject which might be brought within the realms of possibility by the latest computing facilities.

The participants were welcomed by Dr. R. C. Pankhurst, representing the Acting Director of the Laboratory. Prof. B. Thwaites of Southampton University, chairman of the Computer Panel, then gave an introductory talk, in which he outlined the main problems facing the symposium. He suggested that scientists now needed to re-examine their motivations in research-were they interested mainly in mathematical analysis (which, in fluid dynamies, is very difficult) or in numerically expressed results? The answer might be different for the designer and for the 'pure' scientist. In either case, however, it was necessary to take into account the possibility of currently outstanding problems being solved, even within the next ten or twenty years, at tho touch of a button; for this should surely influence the directions which work will take in the intervening period. Thus he emphasized the importance of directing tho discussions towards what will be done in the future.

This was followed by a talk on "The Relevance of Numerical Analysis" by Prof. L. Fox of the University of Oxford. He concerned himself mainly with the finitedifference solution of the relevant types of partial differential equation, paying particular attention to the solu- 